(C) Dereito Vol.29, n02:97-101 (Xullo-Decembro, 2020) • ISSN 1132-9947

\title{
II CONGRESO INTERNACIONAL DERECHO BANCARIO EUROPEO. LA BANCA PÚBLICA DE INVERSIÓN
}

II International Congress on European Banking Law.

Public Investment Banking

DOI: http://dx.doi.org/10.15304/dereito.29.2.7337

\author{
BELÉn AndRÉs SEgovia \\ Doctora en Derecho \\ Universitat de València \\ Belen.andres@uv.es
}

El Paraninfo o también denominado Teatro Académico de la Nau Gran, uno de los lugares más emblemáticos de la Universitat de València, albergó los días 22 y 23 de octubre de 2020, la celebración del II Congreso Internacional sobre Derecho Bancario Europeo. La Banca pública de inversión. Su director, el Dr. D. Juan Antonio Ureña Salcedo, es titular de la nueva cátedra Jean Monnet de la Universitat de València, financiada por el programa Erasmus+ de la Unión Europea, 2020-2023, European banking Public Law, 620731-EPP-1-2020-1-ES-EPPJMO-CHAIR. Gracias a esta condición, ha sido posible la organización del acto otorgándole un merecido reconocimiento no sólo a escala nacional sino también europea.

El hecho de que se trate de la segunda edición no constituye un objeto casuístico. Su organización surge tras el éxito de la primera edición, que versaba sobre "El Derecho bancario de la Unión Europea y el sistema bancario valenciano" y que tuvo lugar los días 24,25 y 26 de octubre de 2018, en la NAU Gran y el Salón de Grados de la Facultat de Dret de la Universitat de València. Los resultados de las investigaciones expuestas, fueron ulteriormente publicadas en un manual titulado Unión Bancaria Europea. Lecciones de Derecho Público, coordinado por el Dr. D. Juan Antonio Ureña Salcedo y publicado por la editorial Iustel, en 2019. Con todo, el Derecho bancario europeo no es estanco. Los interrogantes que se extraen de la crisis económica provocada por la Covid-19 y las insuficiencias reguladoras, que siguen marcando al sector bancario, no pueden ser olvidados. Con este objeto se gestó la segunda edición de 2020, marcada por la excelencia de los ponentes, que combinaban la experiencia teórica y práctica del sector bancario, y su contenido dirigido a la comunidad académica, profesionales en ejercicio y curiosos de este sector. Entre los aspectos innovadores que presidió la segunda edición, encontramos la oferta de una doble vía abierta a la participación: la presencial y la virtual. En la opción presencial, se cuidaron cada una de las recomendaciones sanitarias garantizando así, el adecuado desarrollo del Congreso en la sede central. Por su parte, la participación online fue posible a través de la plataforma Blackboard Collaborate Ultra y otras

Recibido: 20/09/2020. Aceptado: 28/12/2020. 
fórmulas de streaming habilitadas que permitieron seguir en riguroso directo el Congreso.

Señalados todos estos aspectos introductorios, procedemos a anunciar brevemente algunas de las cuestiones y conclusiones que se plantearon. El Congreso comenzó con una apertura institucional que contó con la presencia de tres ilustres representantes del sector económico y académico valenciano: la Dra. Dña. María Vicenta Mestre Escrivá (rectora de la Universitat de València); el $D$. Vicent Soler i Marco (Conseller de Hacienda y Modelo Económico de la Generalitat Valenciana); y el Dr. D. Juan Antonio Ureña Salcedo (Director del Congreso, Director de la Cátedra Jean Monnet y Profesor Titular de Derecho Administrativo de la Universitat de València). Sus intervenciones dieron a conocer la importancia que adquiere la investigación y estos foros para mirar al futuro con optimismo. Finalizada la presentación del acto, iniciaron las exposiciones con cuatro ponencias centradas en: la Banca pública de inversión y la Banca pública de la Unión Europea. El primer bloque, sobre la Banca pública de inversión, comenzó con la exposición realizada por D. Antonio Zafra Jiménez. El ponente advirtió sobre el estado actual de la banca pública y cuál ha sido la posición que ha adoptado, en los últimos tiempos, tras el escenario provocado por la crisis sanitaria. En este sentido, la pandemia ha inducido a que ciertas entidades bancarias observen en la fusión una oportunidad para mantenerse en un mercado, aunque debilitado, ávido de lograr convertirse en un prestador líder. Por ello señaló, la existencia de una regulación excepcional y cómo esta afecta competencia, poniendo el acento en el rol que adquiere la banca pública sobre el sector financiero en su conjunto. Por su parte, D. José María Fernández Martín quiso destacar la importancia de definir qué es el Banco Europeo de Inversión y extraer, desde la experiencia y su marco regulador, las principales conclusiones que nos guían hacia los desafíos que tenemos en la actualidad. Resalta que, entre las instituciones y entidades comunitarias, el Banco Europeo de Inversión dispone de una antigüedad de más de 60 años y sin embargo, pese a su importancia, es una de las menos conocidas. Por último, Juan Alfonso Doménech Gil esbozó que, en estos momentos, nos encontramos en una fase de orientación estratégica donde el ICO desea participar como un eje fundamental. Más allá de su condición de entidad de crédito y de su política económica, busca incorporar, con carácter transversal, la sostenibilidad. Sus objetivos se inclinan de este modo hacia la apuesta por la transición ecológica y digital, teniendo presente la Agenda 2030 fijada por el Gobierno de la nación. El ponente concluyó advirtiendo que todas estas cuestiones ayudarán al cambio de estructura productiva y económica de España que se encuentra hoy a debate en varios foros. En consecuencia, el ICO va a disponer de la taxonomía de la Unión Europea, para la aplicación de sus políticas ad extra y ad intra, relacionadas con la sostenibilidad y los objetivos de desarrollo sostenible.

El segundo bloque, de la presente jornada, centro sus estudios en la Banca pública de la Unión Europea y contó con la moderación de la Dra. Dña. María José Bobes Sánchez. El desarrollo del panel corrió a cargo de 
la Dra. Dña. Rosa María Lastra, que comenzó su exposición realizando algunas reflexiones sobre la banca en general, la banca pública y el orden económico internacional después de Bretton Woods. Esta introducción inicial nos ayudó a comprender como el pasado sirve para aprender de los problemas que plantea la actual crisis sanitaria en relación al marco financiero actual. En el nuevo escenario no debe obviarse, junto al sistema financiero, la oportunidad que ofrece el cambio climático. Por ello, el futuro post-Covid deberá basarse en una economía más digital inteligente-, más verde y más justa. Entre las medidas para poder lograrlo, la ponente citó: la existencia de una cláusula de escape para ayudar a los Estados miembros a la financiación de los diferentes sistemas de salud y de las empresas; normas temporales sobre ayudas estatales para que los gobiernos puedan otorgar liquidez a las empresas y apoyar a los ciudadanos; y surge el SURE como un Programa Europeo de Reaseguro de Desempleo temporal. Por último, señaló la propuesta, realizada por Saule Omarova y Robert Hockett, encaminada a la creación de una Autoridad Nacional de Inversiones, por cuanto permitiría movilizar el capital privado para reconstruir la infraestructura pública de Estados Unidos. La novedad que plantea es que lo haría dentro de los mercados financieros, a través de una subsidiaria de préstamos y una rama separada de capital de riesgos.

La segunda jornada del Congreso, que tuvo lugar el viernes 23 de octubre de 2020, quedó conformada por dos bloques finales, más específicos: la Banca pública en algunos Estados de la Unión y la presentación de comunicaciones. El primero de ellos, la Banca pública en algunos Estados de la Unión, fue coordinado por Dra. Dña Marta Otero Crespo y comenzó con la intervención del Dr. D. Giovani Maria Caruso. Su argumento fue dirigido hacia la necesidad de abordar la posición de los bancos de inversión desde una mirada comparada que surge: del proceso de integración europea y de la ambigüedad existente con respecto a sus competencias. En la actualidad, la Unión Europea ha despojado a los Estados miembros de la competencia que disponían en materia económica, pero al mismo tiempo, no ha asumido directamente estas funciones. Esta realidad ha generado un vacío de poder, debido a que competencias antes existentes actualmente se encuentran en una zona gris, ya que no pertenecen ni a la Unión Europea ni a los Estados miembros. Por esta razón es por la que los diferentes Estados europeos tuvieron que justificar sus intervenciones en la economía asumiendo el papel de inversores. A juicio del ponente, esta era la única forma con la cual poder disimular el interés público tras una fórmula de potencial rentabilidad de la inversión. Concluyó afirmando que, la crisis sanitaria constituye una oportunidad para el cambio en estos aspectos.

Por su parte, el Dr. D. Andrea Pisaneschi destacó como el procedimiento de privatización en Italia cuenta con determinados aspectos particulares. Italia no dispone de bancos públicos en sentido propio. El tema se encuentra en pleno debate. La Banca Italiana, que en su historia ha tenido funciones diferentes pero que se encuentra conectada con proyectos de inversión relacionados con el interés publico, se ha transformado respecto 
a su función original. Esta entidad ha sido señalada como el banco nacional de promoción respecto a la calificación europea. Se trata de una definición un tanto particular, puesto que no es un banco europeo en sentido propio. Con todo, se encuentra sujeto a la regulación del Banco Central Italiano en relación a la regulación informativa y las medidas de reserva obligatoria, pero no respecto a las otras reglas de los bancos ni los requisitos prudenciales respecto al patrimonio. Los cuales constituyen un elemento importante para que pueda tener participaciones no financieras que impactarán en el patrimonio de vigilancia y que, en la actualidad, constituyen un reto que cabe superar.

Siguiendo con el hilo de las ponencias, la Dra. Dña. María José Bobes Sánchez defendió en su discurso que, hasta 2018 la Comisión solo había escogido al Banco Europeo de Inversiones para la gestión indirecta del presupuesto con una salvedad, la Kreditanstalt für Wiederaufbau (en adelante $K f W$ ). El material existente, compuesto por fondos estratégicos y los fondos gestionados por el Plan Juncker, va a constituir una oportunidad para que, estos fondos, se gestionen por los bancos nacionales de promoción. La ponente cree que esta medida dará problemas, puesto que la experiencia de la $K f W$ va a jugar en su favor. Los criterios de elección no parecen ser muy transparentes. Muestra de ello es la existencia de una escasa argumentación que justifique la causa por la que se entregan determinados proyectos a unos bancos nacionales de promoción y no a otros. Este aspecto resulta sumamente novedoso. En consecuencia, la ponente afirmó que los nuevos retos que plantea el escenario actual hacen que tenga que cambiar esta hoja de ruta clásica, debido al papel tan relevante que ocupan los bancos nacionales de promoción.

Sin descuidar algunos de los aspectos señalados por los anteriores ponentes, la Dra. Dña. María Amparo Salvador Armendáriz basó su exposición en dos aspectos de suma relevancia. Por un lado, abordó un recorrido sobre lo que fue la banca pública oficial. Denominación que adoptó durante un dilatado periodo de tiempo la banca pública en España de la que se extrajeron algunas enseñanzas que permitieron dibujar el pasado y adivinar su futuro. Por otro lado, señaló la situación presente de la banca pública en España y su régimen jurídico. En concreto destacó, como el ICO, por su carácter estatutario, no puede recibir fondos del público. Esta situación es a juicio de la ponente algo anacrónica y asimétrica. Esta afirmación se debe a que, aunque se encuentra sometido a los controles y las supervisiones que le corresponden como entidad de crédito por el Banco de España, ya que entiende que el ICO no puede recibir la calificación de una actividad sistémica de la que corresponde su supervisión al Banco Central Europeo, resulta compleja su determinación puesto que el objetivo de la supervisión bancaria junto con la garantía del correcto sistema financiero es la protección de los depositantes. Aspecto que no se da en el caso del ICO. Conviene en consecuencia ser cautelosos a la hora de calificar su posición puesto que de lo contrario nos encontramos supliendo o completando el régimen jurídico que ulteriormente le será de aplicación. 
Por otro lado, el Dr. D. Juan Antonio Ureña Salcedo, realizó un resumen de las exposiciones que habían marcado las dos jornadas y añadió las lecciones que nos aporta la observancia y el análisis de la banca pública en sede autonómica. Puso el acento, entre otros aspectos, en la importancia de la transparencia en el sector financiero como un elemento nuclear y necesario para la ciudadanía, que debe ser analizada a la luz del contexto actual y en relación con deber del secreto y de confidencialidad. Su relevancia se deduce de sus propias consecuencias que se observan, a título de ejemplo, en las diversas denuncias realizadas por el Tribunal de Cuentas dirigidas a determinadas prácticas contrarias a este principio. El último de los ponentes, el Dr. D. Thierry Tanquerel, apuntó la existencia de una banca cantonal Suiza y analizó su regulación estatutaria. La labor que es encomendada al mismo se centra en la garantía de disminuir la inflación, la fijación de rangos a las tasas de interés existente así como poder facilitar la estabilidad económica en el país helvético. También citó a la Autoridad Suiza Supervisora del Mercado Financiero, conocida como FINMA, como el organismo gubernamental suizo responsable de su regulación financiera.

Tras las ponencias, se dio paso al segundo bloque, de la presente jornada, compuesto por un total de cuatro comunicaciones que fueron moderadas por Dña. Julia Narbón Fernández y quien suscribe estas palabras, la Dra. Dña. Belén Andrés Segovia. A modo de resumen, la primera ponencia corrió a cargo del Dr. D. Jorge Correcher Mira, que anunció "Los aspectos penales de la salida en bolsa de Bankia". Tras él, el segundo comunicante, el Dr. D. Pablo Sanz Bayón hizo hincapié en cuál era la situación del "Mercado y política bancaria de China: cambios regulatorios y transformación digital". En tercer lugar, D. Carles Arques Aliaga, señaló la importancia de "La vertebración en la inversión del Banco Europeo de Inversión". Por último, el Dr. D. José Carlos Pedrosa López centró su exposición en "El Pacto Verde Europeo: Repercusiones Bancarias, Legales y Tributarias".

Finalmente, se procedió al acto de clausura del Congreso presidido por el Dr. D. Francisco Palao Gil, que se encontraba en la mesa junto al Dr. D. José Antonio Ureña Salcedo. El Decano de la Facultat de Dret de la Universitat de València, pronunció unas emotivas palabras que guardaban relación con la necesidad de abordar un estudio de estas características y la oportunidad que ofrecen estos encuentros para acercar el conocimiento al conjunto de la ciudadanía. Tras este discurso y la extensión del agradecimiento final por parte del Director del Congreso, se dio por concluido el acto con el anhelo y el deseo, dada su relevancia académica y social, sea la segunda edición de otras muchas que vendrán. 